\title{
Visible Spectrophotometric Analysis Method of Sodium Metamizole in Tablets
}

\author{
CRISTIAN CATALIN GAVAT ${ }^{1 *}$, LEONARD VASILE VASILESCU², AFRODITA DOINA MARCULESCU² \\ ${ }^{1}$ Grigore T. Popa University of Medicine and Pharmacy, Faculty of Medical Bioengineering, Department of Biomedical Sciences, \\ 16 Universitatii Str., 700115, lasi, Romania \\ ${ }^{2}$ Grigore T. Popa University of Medicine and Pharmacy, Faculty of General Medicine, Department of Biochemistry, \\ 16 Universitatii Str., 700115, Iasi, Romania
}

\begin{abstract}
The aim of this research was to exactly quantify pure sodium metamizole from tablets, using a spectrophotometric analysis in Visible range. The method applied has been subjected to a validation protocal which consisted in analyzing the following parameters: linearity of the method, detection limit (LD) , quantitation limit (LQ), Sandell's sensitivity, interference of excipients, stability of prepared solutions, method and system precision, accuracy of the method. Following actual dosing, pure sodium metamizole amount in tablet of pharmaceutical was found to be $477.477 \mathrm{mg}$ assigned to a percentage content of $95.495 \%$, very close to official declared amount $(500 \mathrm{mg})$, with an maximum average percentage deviation of only $4.505 \%$ from the official declared active substance content. This value was situated below the maximum admissible percentage deviation from stated active substance content $( \pm 5 \%)$, established by Romanian Pharmacopoeia, $X$-th Edition rules.
\end{abstract}

Keywords: sodium metamizole, analgesic action, validation protocol, detection limit, quantitation limit

Metamizole (dipyrone, as sodium salt) is a popular analgesic medicine, non-opioid drug, commonly used in human and veterinary medicine. In some cases, this agent is still incorrectly classified as a non-steroidal antiinflammatory drug (NSAID). Metamizole is a pro-drug, which spontaneously breaks down after oral administration to structurally related pyrazolone compounds. Apart from its strong analgesic effect, the medication is an moderate antipyretic and significant spasmolytic agent [1-3].

Today it is known that this drug produces only a very low anti-inflammatory effect, , which is the consequence of its being a very weak cyclooxygenase-1 (COX-1) and cyclooxygenase-2 (COX-2) inhibitor. It is possible that the weak peripheral anti-inflammatory effect of the drug together with the strong inhibition of the centrally located cyclooxygenase-3 (COX-3) are directly connected to the high activity of Fatty Acid Amide Hydrolase (FAAH) in the Central Nervous System (CNS) [1 - 5].

Metamizole acts as a strong pain reliever and the mechanism responsible for the analgesic effect is a complex one, and most probably consists of a central cyclooxygenase-3 (COX-3) effective inhibition at the same time with opioidergic system and cannabinoid system activation. Metamizole can block both Prostaglandine PGdependent and PG-independent pathways of fever induced by lipopolysaccharide (LPS), which suggests that this drug has a profile of antipyretic action distinctly different from that of non-steroidal anti-inflammatory drugs (NSAIDs). Its antipyretic effects are moderate [4-6].

The spasmolytic effect of metamizole is a result of mechanism associated with a powerfull inhibition of intracellular calcium $\left(\mathrm{Ca}^{2+}\right)$ release, as a result of the reduced inositol phosphate synthesis. Metamizole is predominantly applied in the therapy of pain of different etiology, of spastic conditions, especially affecting the digestive tract, and of fever refractory to other treatments. It is especially indicated as an strong, effective analgesic in all types of moderate and intense pain (neuralgia, arthral gia, myalgia, headache, dysmenorrhoea), including postoperative pain, renal and biliary colic, dental pain [37].

Co-administration of morphine and metamizole produces superadditive, antinociceptive effects.. Among the side-effects of metamizole, the most serious one that raises most controversy is the myelotoxic effect. It seems that in the past the risk of metamizole-induced agranulocytosis was exaggerated. Despite the evidence showing no risk of teratogenic and embryotoxic effects, the drug must not be administered to pregnant women, although it is allowed to be given to pregnant and lactating animals [5-7].

The aim of this research was to exactly quantify pure sodium metamizole from tablets of pharmaceutical product marketed as Algocalmin ${ }^{\circledR}$ Zentiva.

To find out effectively pure sodium metamizole in pharmaceutical tablets, a spectrophotometric method in Visible (VIS) range has been developed and proposed to be validated and applied .

Finally, a major objective was to compare the obtained results with Romanian Pharmacopoeia X-th Edition Rules affiliated to international standards, with respect to the maximum permissible deviations from the declared active substance content per tablet provided by pharmaceutical producing company.

\section{Experimental part \\ Method description}

Algocalmin (sodium metamizole) was oxidized by 5.0 $\%$ ammonium orthomolybdate $\left(\mathrm{NH}_{4}\right)_{2} \mathrm{MoO}_{4}$ aqueous solution in a strongly acidic medium $\left(\mathrm{H}_{2} \mathrm{SO}_{4}, 40 \%\right)$, to form a bluish-colored green compound that showed a maximum absorbtion to $\lambda=690 \mathrm{~nm}$. The green-bluish chromogen was obtained in an equivalent amount to sodium metamizole taken into study, so it was dosed spectrophotometrically in Visible range. Chemical reactions that took place were described in figure 1. 
-

Sodium Metamizole

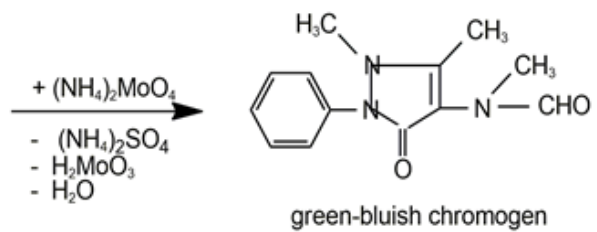

Required chemical reagents and equipment -crystalline pure standard of sodium metamizole pow der supplied by Sigma-Aldrich ${ }^{\circledR}$; -stock solution of sodium metamizole, $1000 \mu \mathrm{g} / \mathrm{mL}$ $(0.1 \mathrm{~g} \%)$, prepared from crystalline pure standard; -working sodium metamizole solution $100 \mu \mathrm{g} / \mathrm{mL}$, obtained from the stock solution $1000 \mu \mathrm{g} / \mathrm{mL}$, by $1: 10$ dilution with distilled water;

-tablets of Algocalmin ® Zentiva containing pure sodium metamizole as active substance, for sample preparation; -ammonium orthomolybdate, $\left(\mathrm{NH}_{4}\right)_{2} \mathrm{MoO}_{4} \quad 5.0 \%$ solution in distilled water;

-sulphuric acid , $\mathrm{H}_{2} \mathrm{SO}_{4} 40 \%$ solution;

-methanol spectral pure p.a.

-UV-Vis spectrophotometer CECIL type, equipped with two glass cuvettes;

- $50 \mathrm{~mL}$ and $100 \mathrm{~mL}$ volumetric flasks;

$-10 \mathrm{~mL}$ graduated glass tubes.

\section{Experimental part}

Visible absorption spectra of green-bluish compound synthetized. Evaluation of maximum absorption wavelength, specific absorptivity and molar absorption coefficient

From standard working sodium metamizole solution $100 \mu \mathrm{g} / \mathrm{mL}$, were accurately measured $0.7 \mathrm{~mL}$ in a graduated test tube of $10 \mathrm{~mL}$, to which $1.5 \mathrm{~mL}$ of ammonium orthomolybdate $\left(\mathrm{NH}_{4}\right)_{2} \mathrm{MoO}_{4}, 5 \%$ and $0.5 \mathrm{~mL}$ of $\mathrm{H}_{2} \mathrm{SO}_{4}, 40 \%$ were added. The content ${ }^{4}$ was stirred well and stored in a dark place for $30 \mathrm{~min}$. A $7 \mu \mathrm{g} / \mathrm{mL}$ solution that contained a green-bluish compound formed following color reaction (fig.1) was obtained. Absorption spectra (fig. 2) was plotted and mean absorbance of colored compound was determined. Specific absorptivity and molar absorption coefficient were calculated (fig.3).

\section{Standard sodium metamizole solutions preparation}

From stock solution of sodium metamizole $1000 \mu \mathrm{g} /$ $\mathrm{mL}(0.1 \mathrm{~g} \%)$, a working solution $100 \mu \mathrm{g} / \mathrm{mL}$ was obtained by 1: 10 dilution to a $100 \mathrm{~mL}$ volumetric flask with distilled water.. From $100 \mu \mathrm{g} / \mathrm{mL}$ solution prepared, 12 volumes were accurately measured into a series of $10 \mathrm{~mL}$ graduated glass tubes, to which were added the coresponding volumes of $5.0 \%\left(\mathrm{NH}_{4}\right)_{2} \mathrm{MoO}_{4}$ and $\mathrm{H}_{2} \mathrm{SO}_{4} 40 \%$ solutions, according to table 2. Thus, 12 standard'solutions of sodium metamizole obtained, were used to calibrate the spectrophotometer at $\lambda=690 \mathrm{~nm}$. Graduated glass tubes were well shaken during $5 \mathrm{~min}$ and stored to a dark place for $30 \mathrm{~min}$. Then, each tube was filled up with distilled water to $10 \mathrm{~mL}$.

Absorbances of standard solutions were measured to maximum absorbtion wavelenght $\lambda=690 \mathrm{~nm}$, against a blank made up of distilled water The obtained values were given in table 2. Five measurements were made and distilled water.
Fig. 1 Chemical reactions of Sodium Metamizole assigned of green-bluish chromogen synthesis average absorbance value was calculated for each standard solution of sodium metamizole. According to mean absorbances obtained values, the calibration graph was plotted (fig. 4) .

Sample synthesis from Algocalmin ( ${ }^{8}$ Zentiva tablets.

One Algocalmin tablet was weighted to find the average mass of pharmaceutical product It was found that mean mass value was $m_{c}=0.5333 \mathrm{~g}$. The official declared content by pharmaceutical company of pure sodium metamizole in tablet was $500 \mathrm{mg}$. Then, 3 tablets were finely crushed and $\mathrm{a}=0.1102 \mathrm{~g}$ of Algocalmin obtained powder were quantitatively brought with a little volume of absolute methanol ( $8 \mathrm{~mL}$ ) into a $\mathrm{V}_{1}=100 \mathrm{~mL}$ volumetric flask. The content was mixed until complete dissolution of sodium metamizole and filled up to the mark with distilled water.

From the obtained sample solution, $v_{1}=0.4 \mathrm{~mL}$ were measured and quantitatively brought to $10 \mathrm{~mL}$ graduated glass tube. Then, $1.5 \mathrm{~mL}$ of ammonium orthomolybdate $\left(\mathrm{NH}_{4}\right)_{2} \mathrm{MoO}_{4}, 5.0 \%$ and $0.5 \mathrm{~mL} \mathrm{H}_{2} \mathrm{SO}_{4}, 40 \%$ were added. (table 3). Sample solution was stirred well, stored in a dark place for 30 min and filled up to volume $V_{p}=10 \mathrm{~mL}$ with

Five measurements have been made and sample mean absorbance Ap, was calculated. (table 3).

\section{Calculation method}

Sodium metamizole concentration $(\mu \mathrm{g} / \mathrm{mL})$ of Algocalmin ${ }^{\circledR}$ sample solution taken into study

From the regression line equation $y=0.0234 x-0.0031$, sample Algocalmin ${ }^{\circledR}$ concentration Cs $(\mu \mathrm{g} / \mathrm{mL})$ was calculated. By replacing $y=A_{s}=$ sample absorbance and $\mathrm{X}=\mathrm{C}_{\mathrm{s}}=$ sample concentration: $A_{s}=0.0234 . C_{s}(\mu \mathrm{g} / \mathrm{mL})-$ 0.0031 and resulted $\left.C_{s}=\left(A_{s}+0.0031\right) / 0.0234 \mu \mathrm{g} / \mathrm{mL}\right)$ (1)., whereas $C_{s}=$ sample concentration and $A_{S}=$ measured absorbance.

Calculation of pure sodium metamizole amount in pharmaceutical tablet

The average measured mass of one tablet of pharmaceutical product was $m_{c}=0.5333 \mathrm{~g}(533,3 \mathrm{mg})$. According to manufacturing company, a pharmaceutical tablet of Algocalmin ${ }^{\circledR}$ contained $500 \mathrm{mg}$ of pure sodium metamizole. The amount of pure sodium metamizole existing in final volume of sample solution $\left(V_{p}\right)$ was determined as follows: $X=C_{s}(\mu \mathrm{g} / \mathrm{mL}) . V_{p}(2)$, whereas $V_{p}=10 \mathrm{~mL}$ has represented sample solution final volume contained in graduated glass tube.

The quantity of pure sodium metamizole from $V_{1}=100$ $\mathrm{mL}$ (volumetric flask) was calculated: $\mathrm{X}_{1}=\left(\mathrm{V}_{1}{ }^{1} \mathrm{X}\right) / \mathrm{V}_{1}$ (3), $v_{1}=0.4 \mathrm{~mL}$ was sample solution volume measured from volumetric flask and quantitatively brought to $V_{p}=$ $10 \mathrm{~mL}$ graduated test tube. 


\begin{tabular}{|c|c|}
\hline Declared content of active substance & $\begin{array}{c}\text { Maximum accepted percentage } \\
\text { deviations }\end{array}$ \\
\hline up to $10 \mathrm{mg}$ & $\pm 10 \%$ \\
\hline $10 \mathrm{mg}$ and up to $100 \mathrm{mg}$ & $\pm 7.5 \%$ \\
\hline $100 \mathrm{mg}$ and over $100 \mathrm{mg}$ & $\pm \mathbf{5} \%$ \\
\hline
\end{tabular}

Table 1

MAXIMUM PERCENTAGE DEVIATIONS FTOM THE STATED CONTENT OF ACTIVE SUBSTANCE IN PHARMACEUTICALS

The amount of pure sodium metamizole in tablet of Algocalmin ${ }^{\circledR}$ was investigated as follows: $Y=\left(m_{c}, X_{1}\right) /$ a (4), whereas $a=0.1102 \mathrm{~g}$ fine powder sample of Algocalmin ${ }^{\circledast}$. prepared from pharmaceutical tablets. $Y$. has represented the amount of pure sodium metamizole in tablet sample, expressed as $\mu \mathrm{g}$ pure sodium metamizole / tablet, then by transforming into $\mathrm{mg}$ pure sodium metamizole / tablet of Algocalmin ${ }^{\circledR}[8-15]$.

Percentage content of pure sodium metamizole in commercial tablet (Z\%): if it was known that one tablet of Algocalmin ${ }^{\circledR}$ had $500 \mathrm{mg}$ of pure sodium metamizole:

$Z=\left(100, Y_{1}\right) / 500(\%)$, so $Z=Y_{1} / 5(\%)(5), Y_{1}$ has been expressed in $\mathrm{mg}$.

Romanian Pharmacopoeia, X-th Edition [10], admitted the following maximum percentage deviations ftom the stated content of active substance in pharmaceuticals, according to the Official European and International in force Rules (table 1)

\section{Statistic study}

A statistic analysis, which sought to investigate some important parameters, was performed. The following steps were taken:

-linearity of the proposed method;

-detection limit (LD) and quantitation limit (LQ);

-Sandell's sensitivity;

-interference test;

-stability of the prepared solutions;

-precision (repeatability and reproducibility) of the method and system precision;

-method accuracy.

\section{Linearity of the method. Regression line parameters}

The linearity of analysis process consisted of the ability to lead to results directly proportional to the concentration of an analyte in a given sample, within a given range (1-40 $\mu \mathrm{g} / \mathrm{mL}$ ) , Practically, the intensity of analytical signal (measured absorbance) has varied in directly proportion to the concentration, for a given area. Correlation coefficient had to be $R>0.999$ and linear regression coefficient $R^{2} \leq$ $0.999[10,11]$. The statistic parameters of method linearity were then determined, using Microsoft Office Excel 2016 software and described in table 4.

Detection limit (LD) was the smallest amount of analyte that could be detected in a sample compared to a blank, under established experimental conditions. It was expressed in the same units as concentration of the analyte $(\mu \mathrm{g} / \mathrm{mL})$ and was evaluated using formula : $L D=3$. SE/ slope (6). SE has represented standard error of the regression line [8- 15].

Quantitation limit ( $L Q)$ was given by the lowest analyte concentration in a sample, which could be quantified (determined) with acceptable precision and accuracy under the same experimental conditions. Its value was expressed in the same units as analyte concentration $(\mu \mathrm{g} /$ $\mathrm{mL}$ ) and was calculated as follows: $L Q=10$. SE / slope (7) $[8-15]$.

Sandell's Sensitivity referred to very small amounts $(\mu \mathrm{g})$ of the drug to be determining, converted to the colored product, which in a column solution of cross section $1 \mathrm{~cm}^{2}$ showed an absorbance value of 0.001 . Sensitivity was expressed as ì $/ \mathrm{cm}^{2}$. Sandell's sensitivity was found to

be practically the concentration $(\mu \mathrm{g} / \mathrm{mL})$ of studied analyte in a sample, which gave an absorbance of 0.001 in a cell of path length $1 \mathrm{~cm}[16,17]$.

Seven target solutions with related concentrations between $1 \mu \mathrm{g} / \mathrm{mL}-34 \mu \mathrm{g} / \mathrm{mL}$ (table) were synthetized from standard working solution $100 \mu \mathrm{g} / \mathrm{mL}$ and were processed in the same manner as standard solutions (table 2) and sample studied solution (table 3). Then, absorbances were measured. to $\lambda=690 \mathrm{~nm}$ Five measurements were performed for each of seven solutions and average absorbances were calculated and reported in table 5. With these values, Sandell's sensitivity was determined as follows: Sandell's Sensitivity (S) $=[$ Concentration of the $\operatorname{drug}(\mu \mathrm{g} / 100 \mathrm{~mL}$ )/Absorbance] $\times 0.001(8)[16,17]$.

Interference test. In pharmaceutical analysis, it was important to test the selectivity towards the excipients and fillers added to the pharmaceutical preparations. Analyzed sodium metamizole was the single active compound in Algocalmin ${ }^{\circledR}$ pharmaceutical product, thus interference of excipients on active substance was investigated. Two solutions were obtained: a reference standard solution 10 $\mu \mathrm{g} / \mathrm{mL}$ was prepared from pure standard crystalline powder of sodium metamizole Merck ${ }^{\circledR}$ without any excipients and a test sample solution was obtained from tablets of the pharmaceutical product Algocalmin ${ }^{\circledR}$ with exactly the same concentration ( $10 \mu \mathrm{g} / \mathrm{mL}$ ) as the reference solution, but containing all the existing excipients [18]. Then, solutions were supplemented with required volumes of the necessary reagents $\left(\mathrm{NH}_{4}\right) \mathrm{MoO}_{4} 5.0 \%$ and $\mathrm{H}_{2} \mathrm{SO}_{4}, 40 \%$ solutions) and processed to the same manner as initial sample and standard solutions. Absorbances of two solutions were measured under the same conditions.

Seven measurements have been made for each of two solutions and related values were shown in (table 6 ). To statistically verify the obtained results, standard deviation (SD) and coefficient of variation or (relative standard deviation, RSD \% ) were calculated: $\operatorname{RSD} \%=\left(S D / X_{\text {mean }}\right)$, $X 100\left(8^{\prime}\right), X_{\text {an }}$ has been represented by the mean of determined absorbances [18]. For accurate measurements, RSD d" 1. Standard deviation SD was calculated by using STDEV function in Microsoft Office Excel 2016.

Stability of the prepared solutions was evaluated by standard deviation (SD) and relative standard deviation (RSD\%) calculation, in order to assess the time required and storage method of studied standard samples, from the preparation time until solutions use. Relative standard deviation (coefficient of variation) RSD $\%$ has been investigated : RSD $\%=(S D \times 100) / X_{\text {averace }}(9)$, whereas $X$ was represented the mean of measured absorbances. For accurate measurements, RSD $\leq 5 \%[8,18-20]$. To analyze the stability in time, a reference sample solution $(5 \mu \mathrm{g} / \mathrm{mL})$ was selected from standard solutions set, and was investigated during $32 \mathrm{~h}$ at room temperature, in normal conditions storage. Storage time and the way of keeping the solutions were appreciated, from the moment of preparation to actual analysis. Five measurements have been made for every investigated time interval and mean absorbances were calculated (table 7). 
Precision of the method or fidelity was a measure of reproducibility of the analysis and was investigated under two aspects: repeatabilityand reproducibility. Repeatability expressed measurements consistency under identical experimental conditions at shorttime intervals (in the same day) while reproducibility replied measurements fidelity under various experimental given conditions at large intervals of time ( in different days) [8,12,14, 18 - 21$]$.

Investigation of reproducibility consisted in carrying out the analysis on a large number of samples from the same set of standard solutions in different days under the same given conditions (intermediate precision) and repeatability measurements consisted in conducting the analysis made on a large number of samples coming from the same set of standard solutions in the same day under the same conditions. Standard deviation (SD) and relative standard deviation (RSD \%) were calculated for the tests carried out in the same day (intra-day) and in different days (interday) $[8,12,14,18$ - 21$]$.

To investigate method precision, three target freshly prepared solutions, chosen from standard solutions set with interest concentrations of 2,10 and $25 \mu \mathrm{g} / \mathrm{mL}$, were taken and have been processed with the same reagents under the same conditions. Then, absorbances were measured to established maximum wavelegth $\lambda=690$ $\mathrm{nm}$. Four separate measurements have been made for each one of the solutions by three times in the same day (intra-day precision) and also four determinations have been made in three different days under experimental conditions (inter-day precision) and mean absorbances values were recorded (table 8 and table 9 )

Calculated concentration $C_{C}(i \mathrm{~g} / \mathrm{mL}$ ) was evaluated from the regression equation line $: \mathrm{y}=0.0234 \mathrm{x}-0.0031$, or $\mathrm{A}=$ 0.0234 . $C_{f}(\mu \mathrm{g} / \mathrm{mL})-0.0031$, from which $C_{c}(\mu \mathrm{g} / \mathrm{mL})=(A$ $+0.0031) / 0.0234$ (10). Recovery (\%) calculated as percentage of the theoretical concentration $C_{T}$, average Recovery value and its variation range has been measured. Recovery $(\%)$ values were estimated with the formula: Recovery $(\%)=\left(C_{c}(\mu \mathrm{g} / \mathrm{mL}) \times 100\right) / C_{T}(\mu \mathrm{g} / \mathrm{mL})(11)[12$ $-15,18-21]$. Standard deviation (SD) was calculated with STDEV function in Microsoft Office Excel 2016 and and relative standard deviation (RSD \%) was estimated using formulas: $R S D \%=(S D \times 100) / R$ (11'), whereas $R_{\text {average }}$ was average Recovery (\%) calcullated value.

aver accurate measurements, average Recovery $R(\%)$ had to be in the following range: $85 \% \leq \mathrm{R} \% \leq 105 \%$, Thus, method precision was expressed as relative standard deviation (RSD \%) of the calculated Recovery $\mathrm{R}(\%)$ values . For accurate determinations, RSD $\leq 5 \%$.

\section{System precision}

For system precision investigation, a target solution of $4 \mu \mathrm{g} . / \mathrm{mL}$ concentration was chosen from the standard solutions set and processed under established experimental conditions. After proper processing under established experimental conditions, this solution was analyzed five times in three different days under given experimental conditions. Mean absorbances obtained values were recorded (table 10). Average absorbance value, standard deviation (SD) and relative standard deviation (RSD \%) were calculated. For appropriate measurements, RSD $\leq 5 \%[16,17]$.

\section{Method accuracy}

In this analysis, the same reference solutions from standard solutions set were chosen: $2 \mu \mathrm{g} / \mathrm{mL}, 10 \mu \mathrm{g} / \mathrm{mL}$ and $25 \mu \mathrm{g} / \mathrm{mL}$ It have been processed with required reagents volumes of $\left(\mathrm{NH}_{4}\right)_{2} \mathrm{MoO}_{4}, 5 \%$ and $\mathrm{H}_{2} \mathrm{SO}_{4}, 40 \%$ under established experimentál conditions. Four investigations for each solution have been achieved in different moments of the same day and absorbances were measured to the known wavelegth value $(\lambda=690 \mathrm{~nm})$ (table 11). Average absorbances, Recovery (\%), minimum and maximum values were calculated. Recovery (\%) values were established using formula (11). Average Recovery (\%) value was determined [ 12 - 15, 18-21 ]. Standard deviation (SD) and relative standard deviation (RSD \%) were calculated in the same manner, using fotmula (11').

Accuracy of the method was a final step in method validation applied to spectrophotometric analysis of sodium metamizole in tablets also from the consistency point of view, by relative error Xd calculation (table 12), which expressed a close correlation between a true, reference value $(\mathrm{Xa})$ and the analytical result obtained from laboratory measurements (Xr). In other words. it was suggested the approximation, proximity or even overlapping between real, reference value and the measured one. Relative error $X_{D}$ was calculated for the same sample concentrations $(2 \mu \mathrm{g} / \mathrm{mL}, 10 \mu \mathrm{g} / \mathrm{mL}$ and $25 \mu \mathrm{g} / \mathrm{mL})$, according to formula:

$$
\mathbf{X d}=\frac{|\mathbf{X r}-\mathbf{X a}|}{\mathbf{X a}}-100 \leq 5 \%, \mathrm{Xr}=\text { measured value (calculated }
$$

concentration), $X a=$ real, true value (theoretical concentration) and $X d=$ relative error. Average relative error $X d_{m}$ was calculated. Relative error accepted value was up to $5 \%$ [12-15, $18-21]$.

\section{Results and discussions}

Visible absorption spectra of green-bluish compound. Maximum absorption wavelength, specific absorptivity and molar absorption coefficient investigation

Absorption spectra of green-bluish chromogen was plotted for $7 \mu \mathrm{g} / \mathrm{mL}$ solution (fig. 2 ) and maximum absorption wavelength was determined to $\lambda=690 \mathrm{~nm}$. Mean measured absorbance value to this wavelength was

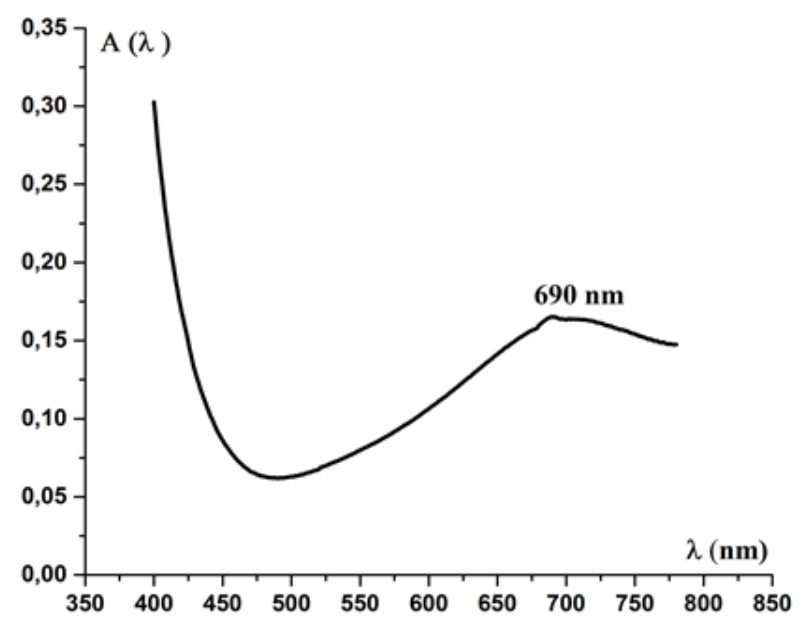

Fig. 2 Absorption spectra (VIS) of sodium metamizole green-bluish derivative

$\mathrm{A}=0.1653$. Concentration of $7 \mu \mathrm{g} / \mathrm{mL}$ was transformed as follows: $7 \mu \mathrm{g} / \mathrm{mL}=0.0007 \mathrm{~g} / 100 \mathrm{~mL}$ and was assigned to a $2.853 .10^{-5}$ mole/ $L$ concentration, with the respect of calculated molecular weight corresponded to green-bluish chromogen, which was $M=245.338 \mathrm{~g} / \mathrm{mole}$ (fig.3).

Linearity of the method-regression line drawing and characteristics

Determined absorbances values of standard solutions measured to $\lambda=690 \mathrm{~nm}$, were listed in table 2 .

With absorbance values of standard solutions set, the calibration graph was plottesd (fig. 4). 


\section{Specific absorptivity:}

According to Lambert-Beer's law: $\mathrm{A}_{\mathrm{lcm}}^{1 \%}=\mathrm{A} / \mathrm{C}(\mathrm{g} / 100 \mathrm{~mL})(\mathrm{l}), \mathrm{C}=0.0007 \mathrm{~g} / 100 \mathrm{~mL}=$ solution concentration $\mathrm{A}=$ calculated mean absorbance $=0.1653$

$A_{1 \mathrm{~cm}}^{1 \%}=$ specific absorptivity

By replacing these values in relation (l), it was obtained: $A_{1 \mathrm{~cm}}^{1 \%}=0.1653 / 0.0007=236.143$. Thus, $A_{1 \mathrm{~cm}}^{1 \%}=236.143$

Fig.. 3 Specific absorptivity and molar absorption coefficient calculation

Molar absorption coefficient: Similarly, $\mathrm{E}_{\text {molar }}=\mathrm{A} / \mathrm{C}(\mathrm{mole} / \mathrm{L})(2), \mathrm{C}=2.853 .10^{-5} \mathrm{~mole} / \mathrm{L}=$ solution concentration

$$
\mathrm{M}_{\text {groxn-bluish compund }}=245.338 \mathrm{~g} / \mathrm{mole}
$$

$\mathrm{A}=$ calculated mean absorbance $=0.1653$

$\mathrm{E}_{\text {molar }}=$ molar absorption coefficient

By replacing these values in relation (2), it was obtained: $\mathrm{E}_{\text {molar }}=0.1653 \cdot 10^{5} / 2.853=5793.901$. Thus, $\mathrm{E}_{\text {molar }}=5793.901$

Table 2

MEASURED ABSORBANCES OF SODIUM METAMIZOLE STANDARD SOLUTUONS

\begin{tabular}{|c|c|c|c|c|c|}
\hline No. det & $\begin{array}{l}\text { mL sodium metamizole } \\
100 \mu \mathrm{g} / \mathrm{mL} \text { (standard) }\end{array}$ & $\mathrm{mL}\left(\mathrm{NH}_{4}\right)_{2} \mathrm{MoO}_{4} 5 \%$ & $\underset{40 \%}{\mathrm{~mL}_{2} \mathrm{SO}_{4}}$ & $\mathrm{C}(\mu \mathrm{g} / \mathrm{mL})$ & $\mathrm{A}(\Lambda)$ \\
\hline 1. & 0.1 & 1.5 & 0.5 & 1.0 & 0.0130 \\
\hline 2. & 0.2 & 1.5 & 0.5 & 2.0 & 0.0432 \\
\hline 4. & 0.4 & 1.5 & 0.5 & 4,0 & 0,0920 \\
\hline 5. & 0.5 & 1.5 & 0.5 & 5.0 & 0.1180 \\
\hline 8. & 2.0 & 1.5 & 0.5 & 20.0 & 0.4620 \\
\hline 9. & 2.5 & 1,5 & 0.5 & 25.0 & 0.5800 \\
\hline 10. & 3.0 & 1.5 & 0.5 & 30.0 & 0.7080 \\
\hline 11. & 3.5 & 1.5 & 0.5 & 35.0 & 0.8120 \\
\hline 12. & 4.0 & 1.5 & 0.5 & 40.0 & 0.9350 \\
\hline
\end{tabular}

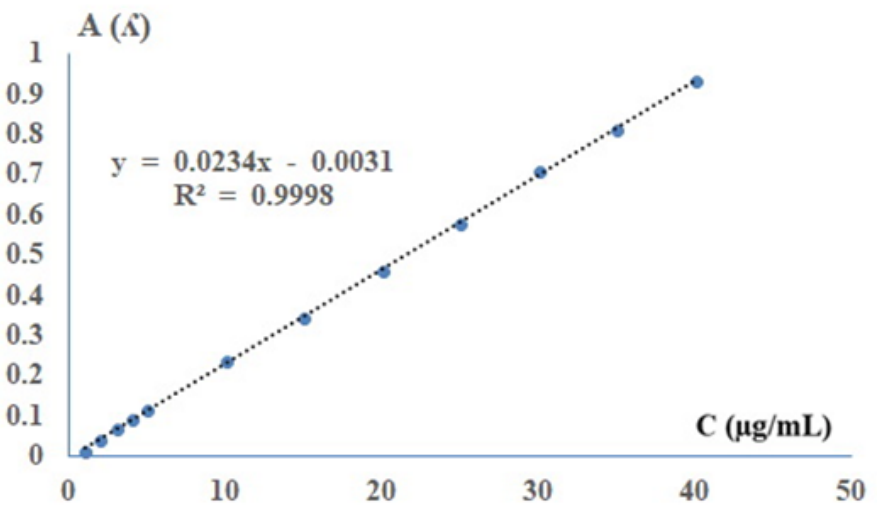

Fig. 4 Regression line obtained for sodium metamizole standard solutions (1-40 $\mu \mathrm{g} / \mathrm{mL}$ )

Investigation of sodium metamizole concentration ( $\mu \mathrm{g} /$ $\mathrm{mL}$ ) in Algocalmin ${ }^{\circledR}$ sample solution

Mean absorbance of Algocalmin ${ }^{\circledR}$ sample containing sodium metamizole as active substance, sodium metamizole concentration which was expressed in $\mu \mathrm{g} /$ $\mathrm{mL}$, as well as the amount of pure sodium metamizole calculated in tablet of pharmaceutical product, were shown in table 3.
From relation (1): $C_{s}=\left(A_{s}+0.0031\right) / 0.0234(\mu \mathrm{g} / \mathrm{mL})$ $=(0.9204+0.0031) / 0.0234$, so $C_{s}=39.466 \mathrm{ig} / \mathrm{mL}$ has represented sample concentration of pure sodium metamizole.

Calculation of pure sodium metamizole amount on pharmaceutical tablet Algocalmin ${ }^{\circledR}$

Pure sodium metamizole amount existing in final volume of sample solution ( $\mathrm{V}_{\mathrm{p}}=10 \mathrm{~mL}$ ) according to equation (2), was: $X=39.466$. $10=394,66 \mu \mathrm{g}$.

Sodium metamizole quantity from $\mathrm{V}_{1}=100 \mathrm{~mL}$ (volumetric flask) was calculated, as follows: $X_{1}=(100$. 394.66) $/ 0.4$, according to relation (3). So, $X_{1}=98665 \mu \mathrm{g}$.

The amount of pure sodium metamizole in tablet of pharmaceutical product : $Y_{1}=(0.5333 .98665) / 0.1102=$ 477477.717 ig sodium metamizole. Thus, $Y_{1}=477,477$ mg pure sodium metamizole / tablet of pharmaceutical Algocalmin ${ }^{\circledR}$.

Percentage content of pure sodium metamizole in commercial tablet ( $Z \%)$ : it is known that one tablet of Algocalmin ${ }^{\circledR}$ had a content of $500 \mathrm{mg}$ pure sodium metamizole, so $Z=477.477 / 5=95.495 \%$. revealed by equation (5). Thus, $Z=95.495 \%$ has expressed sodium metamizole percentage contents in tablet.

Table 3

SAMPLE CONCENTRATION AND SODIUM METAMIZOLE PURE AMOUNTS DETERMINED IN TABLET

\begin{tabular}{|l|c|l|l|l|}
\hline $\begin{array}{c}\text { Algocalmin } \\
\text { sample }\end{array}$ & $\mathrm{As}_{\mathrm{s}}$ & $\mathrm{C}_{s}(\mu \mathrm{g} / \mathrm{mL})$ & $\mu \mathrm{g}$ sodium metamizole /tablet & $\mathrm{mg}$ sodium metamizole /tablet \\
\cline { 2 - 5 } & 0.9204 & 39.466 & 477477.717 & $\mathbf{4 7 7 . 4 7 7}$ \\
\hline
\end{tabular}




\begin{tabular}{|l|l|}
\hline \multicolumn{2}{|l|}{ Regression Statistics } \\
\hline Multiple R (Correlation coefficient) & 0.999898 \\
\hline R Square R ${ }^{2}$ (Linear regression coefficient) & 0.999795 \\
\hline Adjusted R Square R ${ }^{2}$ & 0.999775 \\
\hline Standard Error (SE) & 0.004882 \\
\hline Observations & 12 \\
\hline
\end{tabular}

Table 4

STATISTIC VALUES OF LINEAR REGRESSION PARAMETERS

\begin{tabular}{|c|c|c|c|c|}
\hline Det No. & $\begin{array}{l}\text { Standard solutions } \\
\text { concentration } \\
(\mu \mathrm{g} / \mathrm{mL})\end{array}$ & $\begin{array}{l}\text { Average absorbances } \\
\text { values (A) }\end{array}$ & Sensitivity (S) & $\begin{array}{l}\text { Mean sensitivity } \\
\left(\mathrm{S}_{\mathrm{m}}\right)\end{array}$ \\
\hline 1. & 1.0 & 0.0126 & 0.0794 & \multirow{7}{*}{0.0482} \\
\hline 2. & 3.0 & 0.0696 & 0.0431 & \\
\hline 3. & 8.0 & 0.1879 & 0.0426 & \\
\hline 4. & 12.0 & 0.2827 & 0.0424 & \\
\hline 5. & 17.0 & 0.3890 & 0.0437 & \\
\hline 6. & 27.0 & 0.6259 & 0.0431 & \\
\hline 7. & 34.0 & 0.7880 & 0.0431 & \\
\hline
\end{tabular}

Table 5

SANDELL'S SENSITIVITY
Calculated pure sodium metamizole value has represented $95.495 \%$ from the officially declared value (500 mg) by the pharmaceutical company and it had an average maximum percentage deviation of only $4.505 \%$ from the official pure declared active substance content.

\section{Regression statistic parameters evaluation}

Statistic parameters of method linearity which have been determined in Microsoft Excel 2016, were presented in table 4.

Ecuation of the regression line was: $y=0.0234 . x$ 0.0031 , or $A_{s}(\lambda)=0.0234 . C_{s}(\mu \mathrm{g} / \mathrm{mL})-0.0031$. The intercept was (-) 0.0031 and slope : 0.0234. Linear regression coefficient was $R^{2} \geq 0.999$ and correlation coefficient $R>0,999$ were above minimum admisible value (table 3 ) and were situated within the normal range of values, which demonstrated the linear variation of measured standard solutions absorbances coresponding to their concentrations. Standard error of the regression line (SE) was SE $=0.004882$ (table 3 ) had a coresponding, highly low value.
Detection limit (LD) and quantitation limit (LQ); Detection limit was, $L D=3.0 .004882 / 0.0234$, thus LD $=0.626 \mu \mathrm{g} / \mathrm{mL}$. according to relation (6) and Quantitation limit was assigned with LQ $=10.0 .004882 / 0.0234$, so $\mathrm{LQ}=2.086 \lambda \mathrm{g} / \mathrm{mL}$, from equation (7).

Sandell's sensitivity: method sensitivity test was developed and the results, according to equation (8), were shown in table 5.

Mean sensitivity $\left(S_{m}\right)$ was found to be $S_{m}=0.0482$, a appropriate value which indicated a high method sensitivity. Interference test was performed and obtained results were listed below (table 6).

According to equation ( $\left.8^{\prime}\right), \mathrm{RSD}=0.0394 \%$ and the level of interference was considered highly acceptable, $\mathrm{RSD} \leq 1$.

Stability of the solutions was analyzed for $5 \mu \mathrm{g} / \mathrm{mL}$ standard solution and the results were related in table 7.

Following the calculation (9), it was found $\mathrm{SD}=$ 0.000417 and RSD $=0.355 \%$.

\begin{tabular}{|c|c|c|c|c|}
\hline \multirow{8}{*}{$\begin{array}{l}\text { Reference standard } \\
\text { solution } 10 \mu \mathrm{g} / \mathrm{mL} \\
\text { (without excipients) }\end{array}$} & Absorbances $(A)$ & $\mathrm{X}_{\max }$ & SD & RSD \% \\
\hline & 0.2359 & \multirow{14}{*}{0.23586} & \multirow{14}{*}{$9.2878 \times 10^{-5}$} & \multirow{14}{*}{0.0394} \\
\hline & 0.2359 & & & \\
\hline & 0.2360 & & & \\
\hline & 0.2358 & & & \\
\hline & 0.2359 & & & \\
\hline & 0.2360 & & & \\
\hline & 0.2359 & & & \\
\hline \multirow{7}{*}{$\begin{array}{l}\text { Test sample solution } 10 \\
\mu \mathrm{g} / \mathrm{mL} \text { (with excipients) }\end{array}$} & 0.2358 & & & \\
\hline & 0.2359 & & & \\
\hline & 0.2359 & & & \\
\hline & 0.2357 & & & \\
\hline & 0.2358 & & & \\
\hline & 0.2357 & & & \\
\hline & 0.2359 & & & \\
\hline
\end{tabular}

Table 6

INTERFERENCE TEST VALUES

\begin{tabular}{|c|c|c|}
\hline Det. No. & Time (hours) & $\begin{array}{c}\text { Average value } \\
\mathrm{A}(\lambda)\end{array}$ \\
\hline 1. & 0 & 0.1180 \\
\hline 2. & 2 & 0.1179 \\
\hline 3. & 4 & 0,1178 \\
\hline 4. & 6 & 0,1176 \\
\hline 5. & 12 & 0.1174 \\
\hline 6. & 18 & 0.1172 \\
\hline 7. & 24 & 0.1170 \\
\hline 8. & 32 & 0.1169 \\
\hline \multicolumn{2}{|c|}{ Mean ( $\mathrm{X}_{\text {aver }}$ ) } & 0.117475 \\
\hline \multicolumn{2}{|c|}{ Standard Deviation (SD) } & 0.000417 \\
\hline Relative Standard Deviation (RSD \%) & 0.355 \\
\hline \multicolumn{2}{|c}{} \\
\hline
\end{tabular}

Table 7

STABILITY OF THE SOLUTIONS 
Table 8

INTRA-DAY PRECISION OF SODIUM METAMIZOLE ANALYSIS METHOD

\begin{tabular}{|c|c|c|c|c|c|}
\hline $\begin{array}{l}\text { Theoretical } \\
\text { concentration } \mathrm{C}_{\mathrm{T}} \\
(\mu \mathrm{g} / \mathrm{mL})\end{array}$ & $\begin{array}{c}\text { Mean absorbance } \\
\left(\mathrm{A}_{\mathrm{m}}\right)\end{array}$ & $\begin{array}{c}\text { Calculated concentration } \\
\left(\mathrm{C}_{\mathrm{c})}\right. \\
(\mu \mathrm{g} / \mathrm{mL})\end{array}$ & Recovery (\%) & $\begin{array}{l}\text { Standard } \\
\text { Deviation(S } \\
\text { D) }\end{array}$ & $\begin{array}{l}\text { RSD } \\
(\%)\end{array}$ \\
\hline \multirow{4}{*}{2.0} & 0.0429 & 1.966 & 98.30 & \multirow{12}{*}{1.629} & \multirow{12}{*}{1.629} \\
\hline & 0.0429 & 1.966 & 98.30 & & \\
\hline & 0.0431 & 1.974 & 98.70 & & \\
\hline & 0.0428 & 1.962 & 98.10 & & \\
\hline \multirow{4}{*}{10.0} & 0.2360 & 10.218 & 102.18 & & \\
\hline & 0.2357 & 10.205 & 102.05 & & \\
\hline & 0.2358 & 10.209 & 102.09 & & \\
\hline & 0.2357 & 10.205 & 102.05 & & \\
\hline \multirow{4}{*}{25.0} & 0.5800 & 24.918 & 99.67 & & \\
\hline & 0.5795 & 24.897 & 99.58 & & \\
\hline & 0.5795 & 24.897 & 99.58 & & \\
\hline & 0.5798 & 24.910 & 99.64 & & \\
\hline
\end{tabular}

Table 9

INTER-DAY METHOD PRECISION

\begin{tabular}{|c|c|c|c|c|c|}
\hline $\begin{array}{c}\text { Theoretical } \\
\text { concentration } \mathrm{C}_{\mathrm{T}} \\
(\mu \mathrm{g} / \mathrm{mL})\end{array}$ & $\begin{array}{c}\text { Mean } \\
\text { absorbance } \\
\left(A_{m}\right)\end{array}$ & $\begin{array}{c}\text { Calculated concentration } \\
\mathrm{C}_{\mathrm{C}} \\
(\mu \mathrm{g} / \mathrm{mL})\end{array}$ & Recovery (\%) & $\begin{array}{l}\text { Standard } \\
\text { Deviation } \\
\text { (SD) }\end{array}$ & RSD (\%) \\
\hline \multirow{4}{*}{2.0} & 0.0432 & 1.979 & 98.95 & \multirow{12}{*}{1.395} & \multirow{12}{*}{1.389} \\
\hline & 0.0433 & 1.983 & 99.15 & & \\
\hline & 0.0433 & 1.983 & 99.15 & & \\
\hline & 0.0435 & 1.991 & 99.55 & & \\
\hline \multirow{4}{*}{10.0} & 0.2361 & 10.222 & 102.22 & & \\
\hline & 0.2361 & 10.222 & 102.22 & & \\
\hline & 0.2363 & 10.231 & 102.31 & & \\
\hline & 0.2363 & 10.231 & 102.31 & & \\
\hline \multirow{4}{*}{25.0} & 0.5804 & 24.936 & 99.74 & & \\
\hline & 0.5804 & 24.936 & 99.74 & & \\
\hline & 0.5807 & 24.949 & 99.80 & & \\
\hline & 0.5809 & 24.957 & 99.83 & & \\
\hline
\end{tabular}

Method precision. Measured absorbances of three standard solutions as well as theoretical concentrations $\left(C_{T}\right)$, calculated concetrations $\left(C_{C}\right)$ expressed in $\mu \mathrm{g} / \mathrm{mL}$ and Recovery (\%) values have been represented ( table 8 and table 9).

Average Recovery (\%) value was $\mathrm{R}$, $=100.020 \%$, standard deviation SD $=1.629$ (table). According to $\left(11^{\prime}\right)$, relative standard deviation RSD $=1.629 \%$ was situated within normal limits range.

Average Recovery (\%) was $\mathrm{R}_{\text {ayrage }}=100.414 \%, \mathrm{SD}=$ 1.395 and $\mathrm{RSD}=1.389 \%$ were located within normal limits, RSD $\leq 5 \%$.

System precision was evaluated for $4 \mu \mathrm{g} / \mathrm{mL}$ standard solution and the results obtained were indicated in table 10.

Absorbances coresponding to chosen standard solution

\begin{tabular}{|c|c|}
\hline Det. No. & $\begin{array}{c}\text { Mean aborbance } \\
\mathrm{A}_{\mathrm{m}}(\lambda) \text { values }\end{array}$ \\
\hline 1. & 0,0920 \\
\hline 2. & 0,0924 \\
\hline 3. & 0.0925 \\
\hline 4. & 0.0925 \\
\hline 5. & 0.0922 \\
\hline Mean & 0.092320 \\
\hline SD & 0.000217 \\
\hline RSD (\%) & 0.235 \\
\hline
\end{tabular}

Tabel 10

SYSTEM PRECISION

standard deviation RSD $=0.235 \%$ was within the normal range of values.

\section{Accuracy of the analysis method}

Absorbance values obtained following the have proven to be very close to one another and relative

measurements, calculated concentrations $\left(\mathrm{C}_{\mathrm{c}}\right)$ and Recovery (\%) obtained values, were described in table 11.

\begin{tabular}{|c|c|c|c|}
\hline $\begin{array}{l}\text { Theoretical concentration } \mathrm{C}_{\mathrm{T}} \\
\qquad(\mu \mathrm{g} / \mathrm{mL})\end{array}$ & $\begin{array}{c}\text { Average absorbance } \\
\text { (A) }\end{array}$ & $\begin{array}{c}\text { Calculated } \\
\text { concentration } \mathrm{C}_{\mathrm{c}} \\
(\mu \mathrm{g} / \mathrm{mL})\end{array}$ & Recovery ( $\%)$ \\
\hline \multirow{4}{*}{2.0} & 0.0428 & 1.962 & 98.10 \\
\hline & 0.0428 & 1.962 & 98.10 \\
\hline & 0.0430 & 1.970 & 98.50 \\
\hline & 0.0429 & 1.966 & 98.30 \\
\hline \multirow{4}{*}{10.0} & 0.2357 & 10.205 & 102.05 \\
\hline & 0.2358 & 10.209 & 102.09 \\
\hline & 0.2356 & 10.201 & 102.01 \\
\hline & 0.2355 & 10.197 & 101.97 \\
\hline \multirow{4}{*}{25.0} & 0.5795 & 24.897 & 99.58 \\
\hline & 0.5795 & 24.897 & 99.58 \\
\hline & 0.5798 & 24.910 & 99.64 \\
\hline & 0.5797 & 24.906 & 99.62 \\
\hline
\end{tabular}

Table 11

ACCURACY OF THE METHOD 


\begin{tabular}{|c|c|}
\hline $\mathrm{C}_{\mathrm{T}}(\mu \mathrm{g} / \mathrm{mL})$ & $\mathrm{Xd}(\%)$ \\
\hline \multirow{3}{*}{2.0} & 1.900 \\
\cline { 2 - 2 } & 1.900 \\
\cline { 2 - 2 } & 1.500 \\
\cline { 2 - 2 } & 1,700 \\
\hline \multirow{3}{*}{10.0} & 2.050 \\
\cline { 2 - 2 } & 2.090 \\
\cline { 2 - 2 } & 2.010 \\
\cline { 2 - 2 } & 1.970 \\
\hline \multirow{3}{*}{25.0} & 0.412 \\
\cline { 2 - 2 } & 0.412 \\
\cline { 2 - 2 } & 0.360 \\
\cline { 2 - 2 } & 0.376 \\
\hline
\end{tabular}

Average Recovery (\%) $\mathrm{R}$ average $=99.962 \%$, standard deviation $S D=1.6365$. According to $\left(11^{\prime}\right)$, relative standard deviation RSD $=1.6376 \%$ was located within normal range of values. Minimum Recovery (\%) calculated value was $98.10 \%$ and maximum value: $102.09 \%$ (table).

For full statistical use of obtained results, relative error (Xd \%) was calculated for each of three chosen concentrations. The results are presented in table 12.

Individual values of relative error (table 12??) were below $5 \%$. Average relative error $X d_{m}=1.390 \%$, so Xd ${ }_{m} \hat{A} 5 \%$. was within the normal range of values.

\section{Conclusions}

The method used for Visible spectrophotometric analysis of sodium metamizole in tablets marketed under the name Algocalmin Zentiva ${ }^{\circledR}$, was linear in standard concentrations range $1 \mathrm{Eg} / \mathrm{mL}-40 \mathrm{Eg} / \mathrm{mL}$; the linear regression coefficient was $R^{2}=0.999795, R^{2} \geq 0.999$ and corelation coefficient $R$ $=0.999898, R>0.999$. Standard error of the regression line $S E=0.004882$, detection limit $L D=0.626 \mathrm{Eg} / \mathrm{mL}$ and quantitation limit $L Q=2.086 \mathrm{Eg} / \mathrm{mL}$ were located within the normal range of values.

Investigated spectrophotometric method was highly sensitive; as a result of sensitivity analysis was found average Sandell's sensitivity $S_{m}=0.0482$. The level of excipients interference was considered very acceptable, no interfering was found, RSD $=0.0394 \%, \mathrm{RSD} \leq 1$.

Studied aqeous solutions containing sodium metamizole were very stable at room temperature, in normal storage conditions and could be kept in tightly closed brown bottles at least 32 hours until further analysis. These aspects are highlighted by relative standard deviation value RSD = $0.355 \%$, RSD $\leq 5 \%$.

Precision of the system has ben stated by RSD $=0.235 \%$. Studied analysis method was also highly precise (RSD = $1.629 \%$, intra-day precision and RSD = $1.389 \%$, inter-day precision) and accurate (average Recovery: $\mathrm{R}$ average $=$ $99.962 \%$ and average relative error value: $X d_{m} \stackrel{\text { averags }}{=} 1.390$ $\%)$, It was found all parameters were situated within the accepted range of values (RSD $\left.\leq 5 \% ; X_{m} \leq 5\right)$.

Visible spectrophotometric (VIS) method used for quantitative analysis of sodium metamizole in tablets has been successfully validated through the complete scrolling of studied stages and could be applied in practice to active substance dosing from different samples.

The quantity of pure sodium metamizole in tablet of pharmaceutical was found to be $477.477 \mathrm{mg}$ assigned to a percentage content of $95.495 \%$, very close to official declared amount (500 mg), with an maximum average percentage deviation of only $4.505 \%$ from the official declared active substance content. This value was located below the maximum admissible percentage deviation from the stated active substance content ( $\pm 5 \%)$. As a result, studied pharmaeutical product fell within the normal limits of the Romanian Pharmacopoeia X-th Edition.

\section{References}

1. ANNA, J., TOMASZ, M., JERZY, JAN, J., Polish Journal of Veterinary Sciences, 17, nr. 1, 2014, p 207-214.

2. BURKHARD, H., OLGA, C., JOURI, B., BERTOLD, R., OLIVER, Z., MARTIN, F. ,F., KAY, B., FASEB J ournal, 21, nr. 10, 2007, p 2343-2351. 3.PIERRE, S.,C., SCHMIDT, R., BRENNEIS, C., MICHAELIS, M., GEISSLINGER, G, SCHOLICH, K., British Journal of Pharmacology, 151, 2007, p 494-503.

4. TOBIAS, R., CHRISTIAN, S., AGNES, P., BERNHARD, W., JOEL, S., ARON, H., L., MARIA, G., C., TIZIANA, B., VINCENZO, D., M., ROLF, N., PETER, I., (2012) Bioorganic \& Medicinal Chemistry, 20, nr. 1, 2012, p 101-107.

5.CHANDRASEKHARAN, N., V., HU, D, LAMAR TUREPU, K., R., NATHAN, K., E., J OSHUA, T., TERRY, S., E., DANIEL, L., S., Proceedings of the National Academy of Sciences, U.S.A. , 99, nr. 21, 2002, p 13926-13931. 6. STEPHAN, S., ANDREAS, M., Best Practice \& Research Clinical Anaesthesiology, 21, nr. 1, 2007, p 15-30.

7.MUNIOZ, J, NAVARO, C., NORIEGA, V., PINARDI, G., SIERALTA, F., PRIETO, J.,C., MIRANDA, H.,F., Inflammopharmacology, 18, nr.2, 2010, p 65-71.

8. DORNEANU, V., STAN, M., Chimie Analitica - Lucrari Practice, In: TARCOVEANU , E. (editor), Edit. U.M.F. Gr.T.Popa, lasi, 2000, p. 355359.

9. MONA B., SUBRAHMANYAM, E.,V.,S., SHABARAYA, A.,R., International Journal of Pharma Sciences and Research (IJPSR), 6, nr.2, 2015, p. 411-413.

10.*** Farmacopeea Romana, 10, Edit. Medicala, Bucuresti, 1993, p. 977-1293.

11.KAPIL KALRA (2011). Method Development and Validation of Analytical Procedures, Quality Control of Herbal Medicines and Related Areas, Prof. Yukihiro Shoyama (Ed.),ISBN:978-953-307-6829,InTech,Availablefrom: http://www.intechopen.com/books/qualitycontrol-of-herbal-medicines-and-related-areas/methoddevelopmentand-validation-of-analytical-procedures.

12. ROMAN, L., BOJ ITA, M., SANDULESCU, R., Validarea metodelor de analiza si control, Edit. Medicala, Bucuresti, 1998, p. 75-128,

13. DORNEANU, V., STAN, M., MUSTEATA, M., F., Chimie Analiticã, Edit. U.M.F. Gr.T. Popa, Iasi, 2003, p. 164-500.

14.BOICULESE, L., DIMITRIU, G., , MOSCALU, M.,Elemente de Biostatistica - Analiza statistica a datelor biologice, Edit. PIM, Iasi, 2007, P. 135-156.

15. DORNEANU, V., STAN, M., Metode Chimice si Instrumentale de Analiza, Edit. Universitatii de Medicina si Farmacie Gr.T.Popa, Iasi, 2007, p. 236-332.

16. LAXMI, B., JAY, KUMAR, C., PRABHAT, P., J ournal of Drug Delivery \& Therapeutics; 3, nr. 6, 2013, p., 87-90.

17. MUBEEN, G., VINEETA, P., SOMASHEKAR, P., L., KADRI, U., International J ournal of Chem Tech Research, 1, nr.2, 2009, p. 318321.

18.TULASAMMA, P., VENKATESWARLU, P., Arabian J ournal of Chemistry, 9, Suppl. 2, 2016, p. S 1603- S 1609.

19.KARAM, MOHAMAD, A., ALI, M., MOSTAFA, I., MUSTAFA, B., Indo American Journal of Pharmaceutical Research, 7, nr. 4, 2017, p. 81798184.

20. NITA, A., TIT, D.M., COPOLOVICI, L., MELINTE (FRUNZULICA), C.E., COPOLOVICI, D.M., IOVAN, C., BUNGAU, S.,Rev. Chim. (Bucharest), 69, no. 2, 2018, p. 297-299.

PRADEEP, S., VIKASH, KUMAR, C., PRAVEEN, KUMAR, V., AMIT, KUMAR, S., VIJAY, KUMAR, Y., International Journal of Research and Development in Pharmacy and Life Sciences, 4, nr.1, 2015, p. 13751378

Manuscript received: 16.07 .2018 